University of Nebraska - Lincoln

DigitalCommons@University of Nebraska - Lincoln

USDA National Wildlife Research Center - Staff Publications
U.S. Department of Agriculture: Animal and Plant Health Inspection Service

2011

\title{
Efficacy of ERL-4221 as an ovotoxin for feral pigs (Sus scrofa)
}

\author{
Dustin L. Sanders \\ Texas A\&M University-Kingsville \\ Fang Xie \\ Texas A\&M University-Kingsville \\ Richard E. Mauldin \\ United States Department of Agriculture,,Richard.E.Mauldin@usda.gov \\ Jerome C. Hurley \\ National Wildlife Research Center \\ Lowell A. Miller \\ USDA/APHIS/Wildlife Services' National Wildlife Research Center, Fort Collins, CO, \\ lowell.a.miller@aphis.usda.gov
}

See next page for additional authors

Follow this and additional works at: https://digitalcommons.unl.edu/icwdm_usdanwrc

Sanders, Dustin L.; Xie, Fang; Mauldin, Richard E.; Hurley, Jerome C.; Miller, Lowell A.; Garcia, Michelle R.; DeYoung, Randy W.; Long, David B.; and Campbell, Tyler A., "Efficacy of ERL-4221 as an ovotoxin for feral pigs (Sus scrofa)" (2011). USDA National Wildlife Research Center - Staff Publications. 1338.

https://digitalcommons.unl.edu/icwdm_usdanwrc/1338

This Article is brought to you for free and open access by the U.S. Department of Agriculture: Animal and Plant Health Inspection Service at DigitalCommons@University of Nebraska - Lincoln. It has been accepted for inclusion in USDA National Wildlife Research Center - Staff Publications by an authorized administrator of DigitalCommons@University of Nebraska - Lincoln. 


\section{Authors}

Dustin L. Sanders, Fang Xie, Richard E. Mauldin, Jerome C. Hurley, Lowell A. Miller, Michelle R. Garcia, Randy W. DeYoung, David B. Long, and Tyler A. Campbell 


\title{
Efficacy of ERL-4221 as an ovotoxin for feral pigs (Sus scrofa)
}

\author{
Dustin L. Sanders ${ }^{\mathrm{A}}$, Fang Xie ${ }^{\mathrm{B}}$, Richard E. Mauldin ${ }^{\mathrm{C}}$, Jerome C. Hurley ${ }^{\mathrm{C}}$, Lowell A. Miller ${ }^{\mathrm{C}}$, \\ Michelle R. Garcia ${ }^{\mathrm{B}}$, Randy W. DeYoung ${ }^{\mathrm{A}}$, David B. Long ${ }^{\mathrm{D}}$ and Tyler A. Campbell ${ }^{\mathrm{D}, \mathrm{E}}$ \\ ${ }^{A}$ Caesar Kleberg Wildlife Research Institute, Texas A\&M University-Kingsville, Kingsville, TX 78363, USA. \\ ${ }^{B}$ Department of Animal and Wildlife Sciences, Texas A\&M University-Kingsville, Kingsville, TX 78363, USA. \\ ${ }^{\mathrm{C}}$ United States Department of Agriculture, Animal and Plant Health Inspection Service, Wildlife Services, \\ National Wildlife Research Center, Fort Collins, CO 80521, USA. \\ DUnited States Department of Agriculture, Animal and Plant Health Inspection Service, Wildlife Services, \\ National Wildlife Research Center, Texas A\&M University-Kingsville, Kingsville, TX 78363, USA. \\ ${ }^{\mathrm{E}}$ Corresponding author. Email: tyler.a.campbell@aphis.usda.gov
}

\begin{abstract}
Context. The expansion of feral pig populations across the United States has increased the occurrence of damage and damage complaints. New techniques are needed to more effectively manage feral pig damage, including the development of fertility control agents.

Aims. We aimed to assess the ovotoxic properties of ERL-4221 as a candidate fertility control agent for feral pigs.

Methods. We conducted two palatability trials to determine ERL-4221 acceptance and one experimental trial with ERL4221 at the captive wildlife facility of Texas A\&M University-Kingsville during 2008. Our experimental trial had three treatments, a control containing no ERL-4221, baits containing $16.0 \mathrm{mg}$ ERL-4221 kg $\mathrm{k}^{-1}$ bodyweight for 10 days, and baits containing $16.0 \mathrm{mg}$ ERL-4221 kg $\mathrm{kg}^{-1}$ bodyweight for 20 days.

Key results. Final body mass, total ovary mass, number of follicles and number of corpora lutea did not differ between treatments.

Conclusions. We did not find it efficacious to orally deliver ERL-4221 to feral pigs to reduce fertility. Oral delivery is the most practical, cost-effective means of delivering fertility control agents to feral pigs and development of additional fertility control strategies are needed.

Implications. Unless ovotoxic effects of ERL-4221 can be identified in feral pigs, along with a successful means of administration, other fertility control strategies may need to be explored, such as oocyte-secreted proteins that regulate follicular development.
\end{abstract}

Additional keywords: ERL-4221, fertility control, oocyte, ovary, toxicity.

\section{Introduction}

The recent expansion of feral pig (Sus scrofa) populations across the United States has increased the occurrence of damage and damage complaints by producers, natural resource managers and biologists (Adams et al. 2005). Existing techniques to control feral pig damage in the United States include fencing, diversion, trapping and shooting (Campbell and Long 2009). New techniques are needed to more effectively manage feral pig damage, including the development of toxicants (Cowled et al. 2008) and fertility control agents (Campbell et al. 2010).

4-Vinyl-1-cyclohexene diepoxide (VCD, CAS\# 106-87-6) is an industrial chemical used as a synthetic intermediate and reactive diluent for diepoxides and epoxy resins (Mauldin and Miller 2007). The compound is ovotoxic and has been used extensively to study the process of menopause in humans using mice and rats as biological models (Hoyer et al. 2001).
The compound destroys the oocytes contained within preantral follicles in the ovary, a process thought to be caused by a reduced ability to convert the epoxide to an inactive tetrol in the oocyte (Hoyer et al. 2001). In 2005, the industrial use of VCD was discontinued, both reducing supply and significantly increasing the cost of the compound. Another diepoxide, cycloaliphatic epoxide resin (ERL-4221, CAS\# 2386-87-0), replaced VCD in industrial usage primarily because of lower toxicity, carcinogenicity, volatility and cost (Mauldin and Miller 2007). However, there are no reports on the efficacy of ERL-4221 as an ovotoxin and therefore it is unknown whether it is a possible candidate as a fertility control agent.

Our objectives were to assess the ovotoxic properties of ERL4221 as a candidate fertility control agent for feral pigs and to determine the feasibility of orally delivering ERL-4221 to feral pigs. Because ERL-4221 is structurally similar to VCD (Mauldin and Miller 2007), we predicted that ERL-4221, when delivered on 
a molar concentration basis comparable to VCD levels, might reduce folliculogenesis and ovulation of feral pigs.

\section{Materials and methods}

Our study was conducted at the captive wildlife facility of Texas A\&M University-Kingsville, located $1.5 \mathrm{~km}$ north of Kingsville, Texas. In April 2008, we placed wild caught female feral pigs in individual covered pens $(3.0 \times 3.7 \mathrm{~m})$, where they were maintained throughout the trials. Prior to our trials we collected a blood sample from each animal, separated serum by centrifugation, used the pseudorabies virus (PRV) antibody test kit (Viral Antigens Inc., Memphis, TN) to test for antibodies against PRV, and the buffered Brucella antigen card test (United States Department of Agriculture, Animal and Plant Health Inspection Service, Veterinary Services, Washington, DC) to test for antibodies against Brucella. We did not use antibody-positive pigs in our trials. Water and commercial feed (USDA Pig, Lyssy and Eckels, Poth, TX) were available to animals throughout the study, except during $4 \mathrm{~h}$ fasting periods. All animal handling, care and use procedures were approved by the Institutional Animal Care and Use Committee at Texas A\&M University-Kingsville (permit number 2007-07-20).

We conducted two palatability trials to determine ERL-4221 acceptance and one experimental trial. Throughout these we used strawberry flavoured baits (175-205g) with varying concentrations of ERL-4221. For all trials, each pig received an amount of bait that, if it was all consumed, gave it the specified dose for its actual bodyweight. We added strawberry flavouring (Strawberry Aroma, QualiTech, Chaska, MN) to increase palatability (Campbell and Long 2008). Experimental baits were made at the National Wildlife Research Center and consisted of water, calcium carbonate, surfactant, corn oil, sugar, flavouring, konjac and ERL-4221, where applicable.

For palatability trial 1, which encompassed 13 days, we used three feral pigs. We fasted pigs daily from 0700 to 1100 hours, then introduced baits of known weight at $\sim 1105$ hours and monitored baits for consumption for $\leq 1 \mathrm{~h}$. Baits on days $1-4$, 6, 8, 10 and 12 contained no ERL-4221. Baits on days 5, 7, 9, 11 and 13 contained 7.8, 15.6, 31.25, 62.5 and $125 \mathrm{mg}$ ERL$4221 \mathrm{~kg}^{-1}$ bodyweight, respectively.

To further understand palatability relationships of baits containing ERL-4221, we conducted a second 7-day palatability trial with the same three feral pig individuals. We again fasted animals from 0700 to 1100 hours, then introduced baits of known weight at $\sim 1105$ hours and monitored baits for consumption for $\leq 1 \mathrm{~h}$. Baits on days 1, 2, 4 and 6 contained no ERL-4221. Baits on days 3, 5 and 7 contained 15.6, 20.0 and $25.0 \mathrm{mg}$ ERL-4221 kg-1 bodyweight, respectively.

We designed our experimental trial using acceptable ERL4221 levels determined from the palatability trials. Our experimental trial used 17 feral pigs randomly assigned to one of three treatments. Our control treatment $(n=5)$ consisted of a daily ration of a bait containing no ERL-4221 for 20 days. Our short-duration treatment $(n=6)$ consisted of a daily ration of a bait containing no ERL-4221 for 10 days followed by a daily ration of a bait containing $16.0 \mathrm{mg}$ ERL- $4221 \mathrm{~kg}^{-1}$ bodyweight for 10 days. Our long-duration treatment $(n=6)$ consisted of a daily ration of a bait containing $16.0 \mathrm{mg}$ ERL- $4221 \mathrm{~kg}^{-1}$ bodyweight for 20 days. To accomplish this we fasted animals from 0700 to 1100 hours daily, then introduced baits of known weight at $\sim 1105$ hours and monitored baits for consumption for $\leq 1 \mathrm{~h}$. Following the treatment period ( 20 days), we maintained feral pigs in all treatments groups for an additional 30 days in a post-treatment recovery period. At the end of this period we euthanised the animals with a penetrating captive bolt following approved guidelines (AVMA 2007) and weighed the carcasses. We collected ovaries and determined mass. We then stored ovaries in $10 \%$ formalin. We summed these data from right and left ovaries and report means ( \pm s.e.) with $95 \%$ confidence intervals by treatment.

We quantified the number of primary, secondary, tertiary and pre-ovulatory follicles and the number of corpora lutea on each ovary. Because we did not detect gross morphological differences between right and left ovaries, we analysed only the right ovary for follicular development. We divided formalin-saturated ovarian tissue into $1 \mathrm{mg}$ slices, which we dehydrated through a graded series of ethanol solutions $(40,60,80,95$ and $100 \%)$ for $1 \mathrm{~h}$ each at $4^{\circ} \mathrm{C}$. We transferred tissue from $100 \%$ ethanol solution to xylene for $1 \mathrm{~h}$. We placed the tissue from xylene into a paraffin bath (TissuePrep, Fisher Scientific, Pittsburgh, PA) at $60^{\circ} \mathrm{C}$ for $2 \mathrm{~h}$ and then we embedded tissue in a cassette mould. We sectioned tissue to $6 \mu \mathrm{m}$ and placed tissue on slides (ProbeOn Plus slides, Fisher Scientific) with two serial sections per slide. Following the sectioning process, we deparaffinised and rehydrated tissue through a graded series of ethanol solutions $(100,100,95,95$ and $70 \%$ ) for $2 \mathrm{~min}$ each. We stained tissue sections with hematoxylin dipped in graded series of ethanol $(79,95$ and $100 \%$ ) for $15 \mathrm{~s}$ each and then xylene for $1 \mathrm{~min}$. We dried and mounted sections with Permount (Fisher Scientific) for permanent fixation.

We randomly selected three areas of $13.3 \times 10^{4} \mathrm{~mm}^{2}$ slide $^{-1}$ (six slides per tissue block) to quantify follicles and corpora lutea. We located follicles in the cortex of ovarian tissue and categorised these by stage of development following Oxender et al. (1979) and Griffin et al. (2006): primary follicles, secondary follicles, tertiary follicles and pre-ovulatory follicles. We report mean ( \pm s.e.) number of follicles and corpora lutea with $95 \%$ confidence intervals by treatment.

\section{Results}

During our palatability and experimental trials, feral pigs either consumed all or none of the bait and that no partial consumption was observed. However, animals encountering baits containing $>16.0 \mathrm{mg}$ ERL-4221 kg ${ }^{-1}$ bodyweight often displaying excessive salivation and rigorous head shaking, followed by body rolls on top of the baits.

During palatability trial 1, all feral pigs consumed baits containing $7.8 \mathrm{mg}$ ERL-4221 kg-1 bodyweight, two pigs consumed baits containing $15.6 \mathrm{mg}$ ERL-4221 kg ${ }^{-1}$ bodyweight, and one consumed bait containing $31.25 \mathrm{mg}$ ERL-4221 kg-1 bodyweight. During this trial no animals consumed baits containing $62.5 \mathrm{mg}$ ERL- $4221 \mathrm{~kg}^{-1}$ bodyweight. During palatability trial 2 , all feral pigs consumed baits containing $15.6 \mathrm{mg}$ ERL-422 $\mathrm{kg}^{-1}$ bodyweight and no animals consumed baits containing 20.0 or $25.0 \mathrm{mg}$ ERL- $4221 \mathrm{~kg}^{-1}$ bodyweight. We 
concluded that a palatability threshold exists between 15.6 and $20.0 \mathrm{mg}$ ERL-4221 kg-1 bodyweight, above which feral pigs generally will not consume baits.

During our experimental trial, final body mass of individuals in control $(42.9 \mathrm{~kg}, 95 \%$ CI 29.5-56.3), 10-day (46.7 kg, 95\% CI $39.6-53.8)$ and 20-day treatments $(42.8 \mathrm{~kg}, 95 \%$ CI $35.0-50.6)$ were not statistically different (Fig. 1). Similarly, total ovary mass in control (3.68 g, 95\% CI 1.74-5.62), 10-day (3.82 g, 95\% CI 2.60-5.03) and 20-day treatments (2.92 g, 95\% CI 2.29-3.54) did not differ (Fig. 2). The number of follicles detected in control, 10-day and 20-day treatments did not differ (Fig. 3). Lastly, the number of corpora lutea detected in control $(5.3,95 \%$ CI 2.8-7.8), 10-day (4.4, 95\% CI 2.1-6.7) and 20-day treatments $(3.0,95 \%$ CI 0.4-5.6) were not different (Fig. 4).

\section{Discussion}

In mammals, females are born with a finite number of ovarian primordial follicles containing primary oocytes, which cannot be regenerated when lost (Hoyer et al. 2001). Over the female's lifetime, $>99 \%$ of these primary oocytes will undergo natural

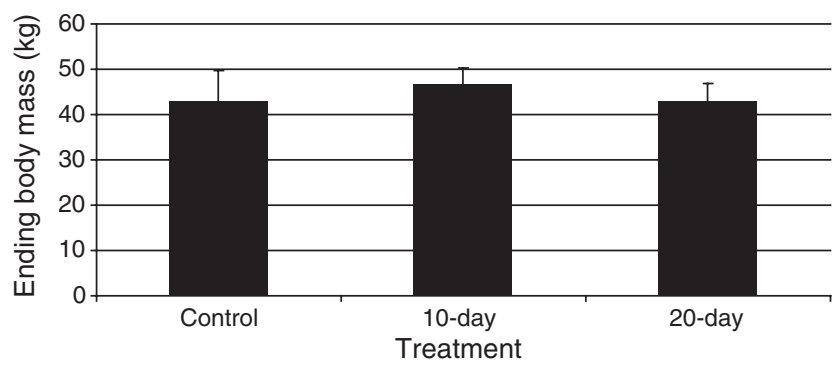

Fig. 1. Mean ( \pm s.e.) final body mass $(\mathrm{kg})$ of female feral pigs in control (no ERL-4221), 10-day and 20-day treatment groups at the captive wildlife facility of Texas A\&M University-Kingsville during 2008. Pigs in the 10-day treatment were fed baits with $16.0 \mathrm{mg}$ ERL-4221 per $\mathrm{kg}$ bodyweight for 10 days. Pigs in the 20-day treatment were fed baits with $16.0 \mathrm{mg}$ ERL-4221 per kg bodyweight for 20 days. atresia (Mayer et al. 2004). Due to the inability of the mammalian ovary to replace atretic follicles, the administration of an ovotoxin provides the opportunity to permanently sterilise a female by destroying oocyte-containing primordial and primary follicles (Hoyer et al. 2001).

For example, in mice and rats, VCD is administered experimentally by daily intraperitoneal injections at concentrations ranging from 40 to $320 \mathrm{mg} \mathrm{kg}^{-1}$ bodyweight for about two weeks (Devine et al. 2004; Mayer et al. 2004; Thompson et al. 2005). Complete or near-complete eradication of ovarian oocytes is achieved at higher doses (Devine et al. 2004). Additionally, female dogs dosed subcutaneously daily for six days with VCD at concentrations ranging from 80 to $240 \mathrm{mg}$ $\mathrm{kg}^{-1}$ bodyweight showed a decrease in the primordial follicle pool 30 days after dosing initiation (Miers et al. 2005). These studies suggest promise for VCD and other diepoxides, such as ERL-4221, as candidate fertility control agents (Mauldin and Miller 2007).

In real-world sterilisation of wild animals, oral administration is a more vaible delivery method than

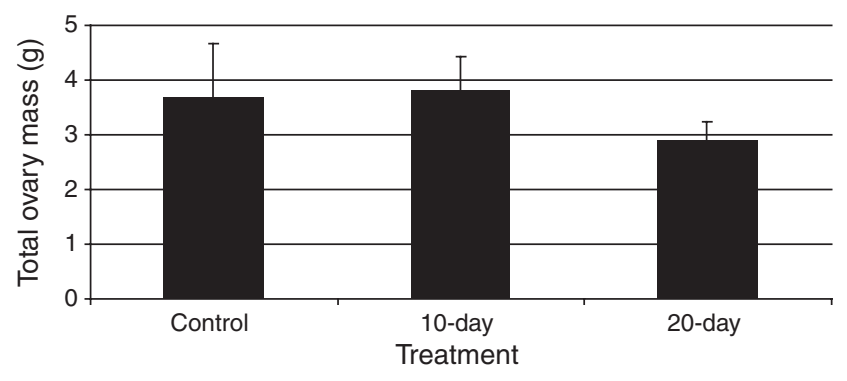

Fig. 2. Mean ( \pm s.e.) total ovary mass (g) of feral pigs in control (no ERL4221), 10-day and 20-day treatment groups at the captive wildlife facility of Texas A\&M University-Kingsville during 2008. Pigs in the 10-day treatment were fed baits with $16.0 \mathrm{mg}$ ERL-4221 per kg bodyweight for 10 days. Pigs in the 20-day treatment were fed baits with $16.0 \mathrm{mg}$ ERL-4221 per $\mathrm{kg}$ bodyweight for 20 days.

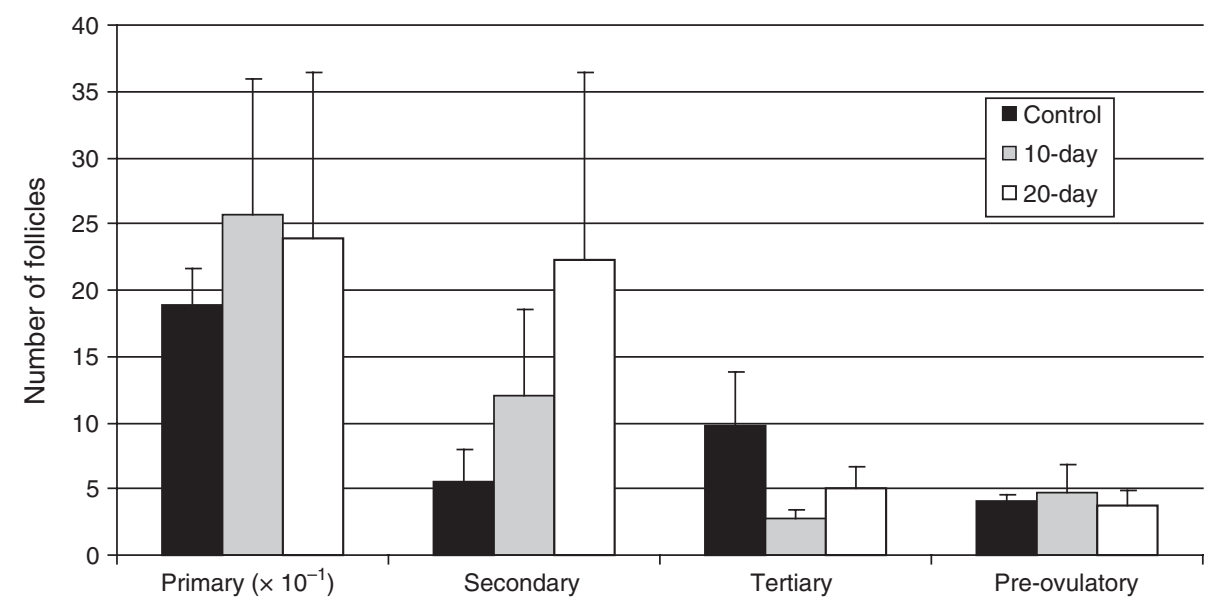

Fig. 3. Mean $( \pm$ s.e. $)$ number of primary $\left(\times 10^{1}\right)$, secondary, tertiary and pre-ovulatory follicles of feral pigs in control (no ERL-4221), 10-day and 20-day treatment groups at the captive wildlife facility of Texas A\&M University-Kingsville during 2008. Pigs in the 10-day treatment were fed baits with $16.0 \mathrm{mg}$ ERL-4221 per kg bodyweight for 10 days. Pigs in the 20-day treatment were fed baits with $16.0 \mathrm{mg}$ ERL-4221 per kg bodyweight for 20 days. 


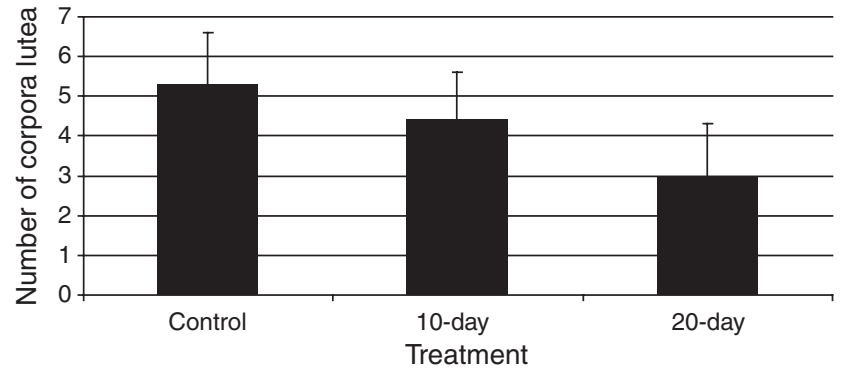

Fig. 4. Mean ( \pm s.e.) number of corpora lutea of feral pigs in control (no ERL-4221), 10-day and 20-day treatment groups at the captive wildlife facility of Texas A\&M University-Kingsville during 2008. Pigs in the 10-day treatment were fed baits with $16.0 \mathrm{mg}$ ERL-4221 per $\mathrm{kg}$ bodyweight for 10 days. Pigs in the 20-day treatment were fed baits with $16.0 \mathrm{mg}$ ERL-4221 per kg bodyweight for 20 days.

catching and injecting wild animals. In addition, for this trial, catching wild pigs every day for up to 15 days would have been very difficult. Feral pigs accepted baits containing $\leq 16.0 \mathrm{mg}$ ERL- $4221 \mathrm{~kg}^{-1}$ bodyweight, a concentration $>2.5$ times less than that used in other studies (Devine et al. 2004). Therefore, we included a longer duration experimental treatment of 20 days. We surmise that our low bait palatability was due to ERL-4221 negatively stimulating the trigeminal nerve of feral pigs. For example, ERL-4221 causes a burning sensation in the oral cavity (R. E. Mauldin, National Wildlife Research Center, pers. comm.).

Twenty days of oral administration of ERL-4221 at $16.0 \mathrm{mg} \mathrm{kg}^{-1}$ bodyweight did not induce any signs of ovotoxicity in feral pigs. Our negative results may be because ERL-4221 is not ovotoxic to pigs, we were not able to deliver sufficient concentrations of ERL-4221 to pigs due to low palatability, we did not expose pigs to ERL-4221 for a long enough duration, or the digestive or metabolic processes in pigs reduces the ovotoxicity of ERL-4221. For example, exposure of ERL-4221 to stomach $\mathrm{pH}$ may have hydrolysed the epoxide groups. Unless these limitations can be addressed, ERL-4221 appears to be an ineffective chemical for fertility control in wild pigs. Regardless, oral delivery is the most practical, cost-effective means of delivering fertility control agents to wild animals (Fagerstone et al. 2006). In this study, ERL-4221 baits did not produce sterility in feral pigs. Data suggest that fertility control methods targeting males only are likely to be inefficient if female promiscuity is high (Delgado-Acevedo et al. 2010); methods targeting females or both sexes jointly may be more effective. Existing fertility control strategies are available for several avian species (e.g. DiazaCon ${ }^{\mathrm{TM}}$ and Nicarbazin) and white-tailed deer (GonaCon ${ }^{\mathrm{TM}}$ ).

\section{Conclusions}

In these trials, it was not efficacious to orally deliver ERL4221 to feral pigs to reduce fertility. Unless the ovotoxic effects of ERL-4221 can be identified in wild pigs, along with a successful means of administration, other fertility control strategies may need to be explored. For instance, a recently developed strategy involves oocyte-secreted proteins that regulate follicular development (Mauldin and Miller 2007). New tools like these may lead to effective control of damaging feral animal populations, such as wild pigs.

\section{Acknowledgements}

Financial support was provided by the United States Department of Agriculture (USDA), Animal and Plant Health Inspection Service, Wildlife Services, National Wildlife Research Center. We appreciate the logistical support provided by the Caesar Kleberg Wildlife Research Institute at Texas A\&M University-Kingsville. Any mention of commercial products herein is for identification purposes and does not constitute endorsement or censure by the USDA.

\section{References}

Adams, C. E., Higginbotham, B. J., Rollins, D., Taylor, R. B., Skiles, R., Mapston, M., and Turman, S. (2005). Regional perspectives and opportunities for feral hog management in Texas. Wildlife Society Bulletin 33, 1312-1320. doi:10.2193/0091-7648(2005)33[1312: RPAOFF]2.0.CO;2

American Veterinary Medical Association (AVMA) (2007). 'AVMA Guidelines on Euthanasia.' (American Veterinary Medical Association: Schraumburg, IL.)

Campbell, T. A., and Long, D. B. (2008). Mammalian visitation to candidate feral swine attractants. The Journal of Wildlife Management $\mathbf{7 2}$, 305-309. doi:10.2193/2007-227

Campbell, T. A., and Long, D. B. (2009). Feral swine damage and damage management in forested ecosystems. Forest Ecology and Management 257, 2319-2326. doi:10.1016/j.foreco.2009.03.036

Campbell, T. A., Garcia, M. E., Miller, L. A., Ramirez, M. A., Long, D. B., Marchand, J., and Hill, F. (2010). Immunocontraception of male feral swine with a recombinant GnRH vaccine. Journal of Swine Health and Production 18, 118-124.

Cowled, B. D., Elsworth, P., and Lapidge, S. J. (2008). Additional toxins for feral pig (Sus scrofa) control: identifying and testing Achilles' heels. Wildlife Research 35, 651-662. doi:10.1071/WR07072

Delgado-Acevedo, J., Zamorano, A., DeYoung, R. W., Campbell, T. A., Hewitt, D. G., and Long, D. B. (2010). Promiscuous mating in feral pigs (Sus scrofa) from Texas, USA. Wildlife Research 37, 539-546. doi:10.1071/WR10052

Devine, P. J., Sipes, I. G., and Hoyer, P. B. (2004). Initiation of delayed ovotoxicity by in vitro and in vivo exposure of rat ovaries to 4vinylcyclohexene diepoxide. Reproductive Toxicology (Elmsford, N.Y.) 19, 71-77. doi:10.1016/j.reprotox.2004.06.002

Fagerstone, K. A., Miller, L. A., Bynum, K. S., Eisemann, J. D., and Yoder, C. (2006). When, where and for what wildlife species will contraception be a useful management approach? Proceedings of the Vertebrate Pest Conference 22, 45-54.

Griffin, J., Emery, B. R., Huang, I., Peterson, C. M., and Carrell, D. T. (2006). Comparative analysis of follicle morphology and oocyte diameter in four mammalian species (mouse, hamster, pig, and human). Journal of Experimental \& Clinical Assisted Reproduction 3, 2. doi:10.1186/ 1743-1050-3-2

Hoyer, P. B., Devine, P. J., Hu, X., Thompson, K. E., and Sipes, I. G. (2001). Ovarian toxicity of 4-vinylcyclohexene diepoxide: a mechanistic model. Toxicologic Pathology 29, 91-99. doi:10.1080/019262301301418892

Mauldin, R. E., and Miller, L. A. (2007). Wildlife contraception: targeting the oocyte. In 'Managing Vertebrate Invasive Species: Proceedings of an International Symposium'. (Eds G. W. Witmer, W. C. Pitt and K. A. Fagerstone.) pp. 434-444. (National Wildlife Research Center: Fort Collins, CO.) 
Mayer, L. P., Devine, P. J., Dyer, C. A., and Hoyer, P. B. (2004). The follicledepleted mouse ovary produces androgen. Biology of Reproduction 71, 130-138. doi:10.1095/biolreprod.103.016113

Miers, H., Dyer, C., Craig, R., Kalleco, D., Karr, K., Robinson, Z., Marion, S., Hoyer, P., Blalock, C., and Mayer, L. (2005). 4-Vinylcyclohexene diepoxide-induced primordial follicle depletion in canine ovaries. In 'Proceedings of the Symposium of the 38th Annual Meeting of the Society of the Study of Reproduction'. (The Society of the Study of Reproduction: Quebec City, Canada.)

Oxender, W. D., Colenbrander, B., Van de Wiel, D. F. M., and Wensing, C. J. G. (1979). Ovarian development in fetal and prepubertal pigs. Biology of Reproduction 21, 715-721. doi:10.1095/biolreprod21.3.715
Thompson, K. E., Bourguet, S. M., Christian, P. J., Benedict, J. C., Snipes, I. G., Flaws, J. A., and Hoyer, P. B. (2005). Differences between rats and mice in the involvement of the aryl hydrocarbon receptor in 4vinylcyclohexene diepoxide-induced ovarian follicle loss. Toxicology and Applied Pharmacology 203, 114-123. doi:10.1016/j.taap.2004. 07.010

Manuscript received 29 September 2010, accepted 21 March 2011 